\title{
Primary intracranial extra-skeletal myxoid chondrosarcoma of right lateral ventricle with EWSR1 gene fusion: a case report and review of literature
}

\author{
Vinodh Kumar Selvaraj ${ }^{1}$, Deleep Kumar Gudipudi ${ }^{1}$, Rachna Khera ${ }^{2}$ and Sudha Murthy ${ }^{2}$ \\ ${ }^{1}$ Department of Radiation Oncology, Basavatarakam Indo-American Cancer Hospital and Research Institute, Road number 10, Banjara Hills, \\ Hyderabad-500034, Telangana, India \\ ${ }^{2}$ Department of Pathology, Basavatarakam Indo-American Cancer Hospital and Research Institute, Road number 10, Banjara Hills, Hyderabad-500034, \\ Telangana, India
}

\section{Abstract}

Background: Primary intracranial malignancies with extra-skeletal myxoid chondrosarcoma (EMC) features are extremely rare. EMC constitutes a distinct genomic entity characterised by reciprocal translocation of fusion genes, most commonly EWS RNA Binding Protein 1 (EWSR1) in 22q12 with Nuclear Receptor Subfamily 4 Group A Member 3 (NR4A3) in 9q2-q31.1. It is reported to have a high propensity for local recurrence and has potential for metastasis. So far in 28 years since its first description, only 17 cases of primary intracranial EMC were reported in literature. This would be the second case of intraventricular origin and first case from lateral ventricle.

Case presentation: A 27-year-old male presenting with complaints of headache, seizures and pain in neck was diagnosed to have a mass lesion in right lateral ventricle in Magnetic Resonance Imaging of brain. He underwent right parieto-occipital craniotomy with total excision of the lesion. Initial histopathological examination was reported as Ependymoma, WHO grade II. However, blocks and slides review with immunohistochemistry (IHC) markers revealed neoplastic aetiology with extensive myxoid changes. Hence, fluorescent in-situ hybridisation (FISH) testing was done with EWSR1 break apart probe, which demonstrated EWSR1 break apart signals. Therefore, correlating the clinical findings with morphology, IHC and FISH, the diagnosis of primary intracranial EMC was rendered. Patient received adjuvant external beam radiation of $54 \mathrm{~Gy}$ in 30 fractions to the post-op region. At 29-month follow-up, there was no evidence of disease recurrence.

Conclusions: Owing to the rarity of the condition, there are no standard treatment guidelines available for primary intracranial EMC. A combined treatment approach with surgery followed by adjuvant radiotherapy provides good local control with less morbidity.

Keywords: EWSR1 gene fusion, extra-skeletal myxoid chondrosarcoma, intracranial myxoid neoplasm, rare intracranial malignancy

\section{Background}

Cartilaginous tumours constitute about $0.16 \%$ of intracranial neoplasms [1]. Primary cranial chondrosarcoma usually arises from synchondroses of skull base, especially the clival

Correspondence to: Dr Vinodh Kumar Selvaraj Email: vinodhkumar.selva@gmail.com

ecancer 2021, 15:1257

https://doi.org/10.3332/ecancer.2021.1257

Published: 30/06/2021

Received: 10/12/2020

Publication costs for this article were supported by ecancer (UK Charity number 1176307).

Copyright: (c) the authors; licensee ecancermedicalscience. This is an Open Access article distributed under the terms of the Creative Commons Attribution License (http:// creativecommons.org/licenses/by/4.0), which permits unrestricted use, distribution, and reproduction in any medium, provided the original work is properly cited. 
basiocciput and the sphenoid bone [1-3]. Myxoid chondrosarcoma is a variant of chondrosarcoma which lacks hyaline cartilage areas and has cells arranged in cords in abundant myxoid stroma [4,5]. They usually occur in lower extremities and very rarely present as primary intracranial lesion [6]. Over past 28 years, since the first description of myxoid chondrosarcoma in 1972, there are only 17 cases of intracranial extra-skeletal myxoid chondrosarcoma (EMC) reported in literature. The intracranial sites of origin were cerebellopontine angle, cerebellum, dura, fourth ventricle, pineal gland, falx cerebri and brain parenchyma [7-23]. Among the reported cases, there was only one case of intraventricular origin, which originated from fourth ventricle [7]. The case reported here will be the 18th case overall in literature, the second case of intra-ventricular origin and the first case of lateral ventricular origin. Here, we describe a case arising from right lateral ventricle in a 27-year-old male, initially thought to be ependymoma, treated with surgery followed by adjuvant radiotherapy. We also discuss when to consider EMC as a possible differential, pathological findings, differential diagnosis and treatment results.

\section{Case presentation}

A 27-year-old male evaluated elsewhere for complaints of headache, seizures and neck pain. Magnetic resonance imaging (MRI) of spine did not reveal any abnormality, whereas MRI brain showed a well-defined lobulated T1 hypointense, T2 heterogeneously hyperintense mass lesion of size $3.5 \times 3.7 \times 3.6 \mathrm{~cm}$ in atrium of the right lateral ventricle causing mass effect in form of dilated occipital and temporal horns of right lateral ventricle and midline shift of $11 \mathrm{~mm}$ towards left (Figure 1). Moderate perifocal oedema and homogenous intense enhancement on contrast administration were noted. Based on MRI findings, a differential diagnosis of choroid plexus papilloma, meningioma and sub-ependymal giant cell astrocytoma was considered. He underwent right parieto-occipital craniotomy with total excision of the lesion. Post-operative histopathological examination was suggestive of ependymoma, tanycytic variant, WHO grade II. He was then referred to our institute for adjuvant radiation. On clinical examination, he had no neurological deficit. MRI brain showed a well-defined lobulated nonenhancing cystic lesion of CSF intensity on all sequences in right parietal lobe communicating with right lateral ventricle with dilated temporal and occipital horn (Figure 2). There was no evidence of focal enhancing areas and was suggestive of post-operative gliosis. As the initial histopathological diagnosis was ependymoma, we performed a CSF cytology examination which was negative.

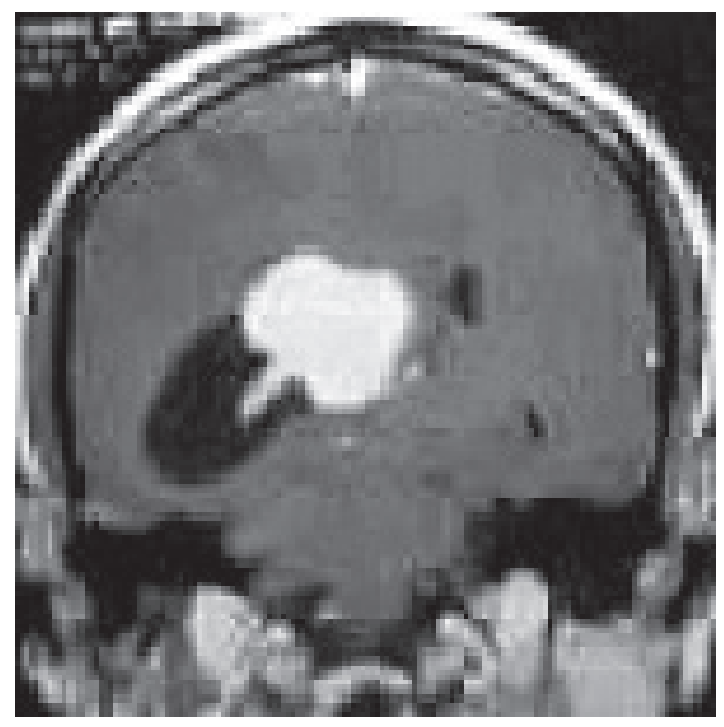

Figure 1. Pre-op MRI Brain, T2W coronal section showing a well-defined lobulated hyperintense mass lesion in atrium of the right lateral ventricle causing mass effect in form of dilated occipital horn of right lateral ventricle. 
The postoperative blocks and slides were reviewed in our hospital. Histopathology revealed fragments of lesion with cells arranged in cords and focally in sheets in abundant myxoid stroma. The tumour cells were ovoid to spindle shaped with ovoid nuclei and specked chromatin and moderate bipolar cytoplasm. Focal perivascular arrangement of tumour cells was seen. No significant atypia, mitosis or necrosis identified. A provisional diagnosis of neoplastic aetiology with extensive myxoid change was rendered warranting immunohistochemistry (IHC) examination. IHC with vimentin, cluster of differentiation (CD99), revealed positive results, while Glial Fibrillary Acidic Protein (GFAP), pancytokeratin, CD34, S100 were negative and Ki67 proliferation index was low (1\%-2\%) (Figure 3). Subsequently fluorescent in-situ hybridisation (FISH) for EWS RNA Binding Protein 1 (EWSR1) gene rearrangement was carried out which revealed positive results. Final possibilities considered were myxoid chondrosarcoma or primary intracranial myxoid neoplasm with EWSR1 fusion.

Owing to the extremely rare occurrence of the disease, case was discussed in multi-disciplinary tumour board and planned for post-operative radiation. Patient was immobilised with a thermoplastic head mask in a supine position and contrast-enhanced CT was taken at $3 \mathrm{~mm}$ thickness on a Philips Big bore CT Scan machine. Images were exported to ECLIPSE Treatment Planning system. Pre-op and post-op MRIs were fused with the Planning CT images. Contouring was done on fused images, post-operative bed along with organ at risk (eyes, brainstem, temporal lobe, optic chiasm, lens, cochlea, optic nerves and pituitary gland) was delineated. A planning target volume was generated around the clinical target volume. A dose of $54 \mathrm{~Gy}$ in 30 fractions at $1.8 \mathrm{~Gy}$ per fraction using $6 \mathrm{MV}$ photons was delivered to the patient using RapidArc image-guided radiotherapy technique. Patient tolerated treatment well with grade 1 skin reactions and alopecia at the treated site. At 29 months follow-up, patient had no neurological deficit and MRI brain showed no evidence of disease recurrence.

\section{Discussion}

Extra-skeletal cartilaginous tumours are thought to be derived from primitive mesenchymal cells or embryonal rests of cartilaginous matrix within the bone or a result of metaplasia of fibroblasts [24, 25]. Histologically, there are three variants extra-skeletal cartilaginous tumours: classical, mesenchymal and myxoid [4, 5]. Classical variant is rare, tends to occur in older age group and has a better prognosis [25-27]. Whereas mesenchymal variant usually occurs in younger age group and has higher propensity for frequent local recurrences or metastatic disease [27-29]. Myxoid chondrosarcoma was first described by Enziner and Shiraki in 1972 as a deep soft tissue tumour of the extremities [30]. EMC is a distinct genomic entity with an indolent course but with potential for local recurrence and distant metastasis [31]. Sometimes, it is found to be associated with hereditary syndromes such as Ollier disease and Maffucci syndrome [27, 32].

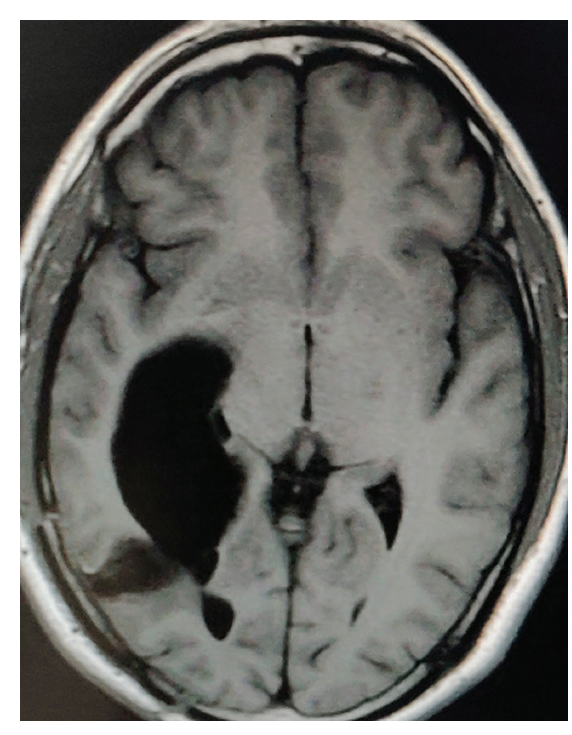

Figure 2. Post-op MRI Brain, T1W axial section showing a well-defined lobulated non-enhancing cystic lesion in right parietal lobe communicating with right lateral ventricle with dilated occipital horn. 


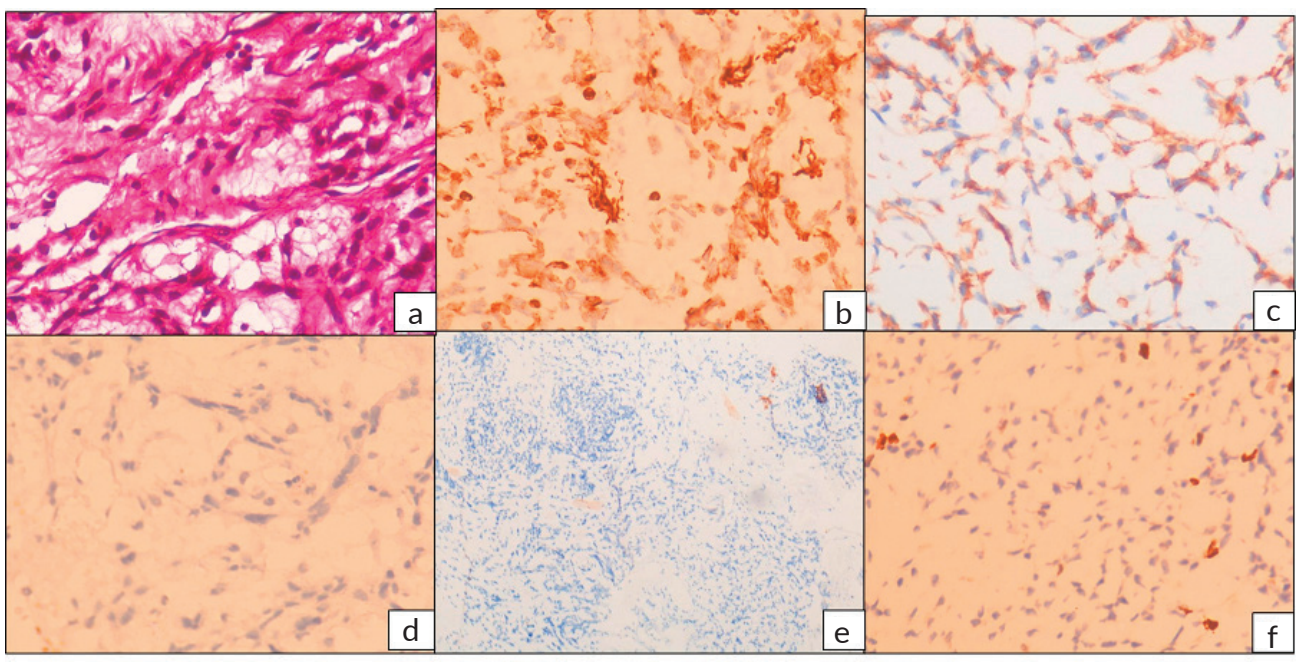

Figure 3. (a): Haematoxylin and eosin (H\&E) stained sections showing tumour cells arranged in cords in abundant myxoid stroma. The tumour cells have ovoid nuclei and specked chromatin and moderate bipolar cytoplasm. (H\&E 400x) IHC revealed tumour cells to be positive for (b): vimentin and (c): CD99, while (d): GFAP, (e): S100, CD34 and Pancytokeratin (not shown) were negative and (f): Ki-67 proliferation index was low, $1 \%-2 \%$.

The symptomatology of EMC is extremely non-specific. It is consistent with any brain lesion with headache, seizures, focal neurological deficit and symptoms due to mass effect/midline shift. MRI is the standard imaging modality of choice. In MRI, primary intracranial EMCs are seen as hypointense well-demarcated lesions in T1-weighted images with slightly higher signal intensity in T2-weighted images and generally lack surrounding oedema [10,12-14]. The close differentials to be considered are meningioma or metastatic disease [18, 33]. Therefore, it is always mandatory to make a histological diagnosis before treatment. IHC panel of markers such as vimentin, cytokeratin, S100 and GFAP play a vital role in histopathological diagnosis. Vimentin positivity and cytokeratin negativity were reported in most cases of primary intracranial EMC in literature [14, 17, 18, 21]. S100 negativity helps to rule out chordoma [34]. EWSR1 gene fusion in FISH testing with IHC markers favours the diagnosis of EMC.

In the case discussed above, the patient presented with headache, seizures and neck pain. Both clinical and MRI findings were nonspecific. A diagnosis of EMC was never considered at any stage of clinical evaluation. The morphologic diagnosis of ependymoma was rendered at a community centre presumably based on ovoid cells with few bland elongated nuclei and location of the tumour being lateral ventricle. However, when it was reviewed at our centre, the young age, bland appearance of tumour cells which were round to ovoid in a myxoid matrix associated with cord like arrangement, negativity for GFAP \& epithelial markers, and strong vimentin \& CD99 (membrane) positivity by IHC led us to consider this to be a sarcoma, particularly a myxoid sarcoma (myxoid liposarcoma, myxofibrosarcoma, myxoid angiomatoid fibrous histiocytoma (AFH), intracranial myxoid sarcoma with EWSR1 translocations). Since we had the EWSR1 break apart probe, we were compelled to do FISH for EWSR1 which demonstrated EWSR1 break apart signals. The differential diagnosis at this juncture consisted of all intracranial myxoid lesions with EWSR1 translocation. The possibility of myxoid (AFH) was ruled out as there was no lymphocytic cuffing or prominence of vasculature. Myxoid liposarcoma was also ruled out due to morphology of cells that lack lipoblasts and no S100 staining. The possibility of myoepithelial carcinoma needs to be ruled out in this setting which was negated by cytokeratin AE1/AE3 and S100 expression by IHC. The other fusion partners of EWSR1 in intracranial myxoid sarcomas include cyclic-AMP response element-binding protein 1 (CREB1), cyclic-AMP response element modulating protein (CREM) and Activating Transcription Factor 1 (ATF1) of which CREB1 being the most common. The Proliferation index (Ki 67) also was substantially low which corroborated with the indolent behaviour of EMC, presumably a tumour with EWSR1-Nuclear Receptor Subfamily 4 Group A Member 3 (NR4A3) fusion. However, NR4A3 by FISH was not available at any centre in the country at that point in time. Therefore, correlating the clinical findings with morphology, IHC and FISH, the diagnosis of EMC was rendered. 
About two thirds of EMC show chromosomal reciprocal translocation $t$ (9;22) q22: q12 resulting in the fusion of EWSR1 gene to NR4A3 [35-37]. A smaller proportion of EMC tumours are known to harbour TATA-Box Binding Protein Associated Factor 15 (TAF15)-NR4A3 fusions which are known to show high grade features morphologically. The other fusion partners of EWSR1 in intracranial myxoid sarcomas include CREB1, CREM and ATF1 with CREB1 being the most common. Custom made probes for NR4A3 gene were used for NR4A3 locus on chromosome 9q22 in a case report of EMC to study EWSR1-NR4A3 fusions [37].

On literature review, surgery has been the first treatment modality of choice for primary intracranial EMC. Either total or subtotal resection of tumour was done in all cases depending on site and extent of the tumour (Table 1) [7-23]. Adjuvant radiotherapy was advocated in most of the cases. Different modalities of radiotherapy such as radioactive iodine brachytherapy, external beam photon therapy or proton therapy were utilised (Table 1). As summarised in Table 1, the adjuvant radiation dose with photons ranged from 54-60.8 Gy in 28-33 fractions [10, $14-16,18,21,22]$. In a single case treated with protons, a dose of 66 CGE was delivered [20]. Adjuvant chemotherapy such as ifosfamide and temozolomide was administered in two patients but their role in EMC is doubtful [18, 21]. Therefore, in the case reported, we delivered adjuvant radiotherapy of $54 \mathrm{~Gy}$ in 30 fractions following total surgical resection of the lesion done elsewhere.

Table 1. Primary intracranial EMC cases reported in literature.

\begin{tabular}{|c|c|c|c|c|c|}
\hline $\begin{array}{c}\text { First } \\
\text { author/year }\end{array}$ & $\begin{array}{c}\text { Age } \\
\text { (year)/sex }\end{array}$ & Location & Surgery & $\begin{array}{l}\text { Adjuvant } \\
\text { treatment }\end{array}$ & Outcome \\
\hline Scott et al [7] & $39 / \mathrm{M}$ & Fourth ventricle & STR & Nil & 13 days, died (ventriculitis) \\
\hline $\begin{array}{l}\text { Smith and } \\
\text { Davidson [8] }\end{array}$ & $12 / \mathrm{M}$ & $\begin{array}{l}\text { Cerebellum and } \\
\text { meninges }\end{array}$ & CR & Nil & 13 months, no recurrence \\
\hline Salcman et al [9] & $28 / F$ & $\begin{array}{l}\text { Left parafalcine and } \\
\text { dura of falx }\end{array}$ & CR & Nil & $\begin{array}{l}\text { At } 10 \text { months, recurrence - Surgery followed } \\
\text { by radioactive } 125 \text { I Brachytherapy } 20 \text { months, } \\
\text { no recurrence, alive }\end{array}$ \\
\hline Sato et al [10] & $43 / \mathrm{F}$ & Pineal gland and dura & STR & $\begin{array}{l}\text { RT ( } 60 \text { Gy in } 30 \text { fractions) and } \\
\text { chemotherapy }\end{array}$ & 3 years, tumour progression, died \\
\hline Sala et al [11] & $55 / F$ & Petrooccipital dura & CR & Nil & $\begin{array}{l}\text { Recurrence at } 10,16,31 \text { and } 43 \text { months - } \\
\text { Repeated surgery } \\
7 \text { years, died }\end{array}$ \\
\hline $\begin{array}{l}\text { Gonzalez- } \\
\text { Lois et al [12] }\end{array}$ & $17 / F$ & $\begin{array}{l}\text { Frontotemporal lobe } \\
\text { and dura }\end{array}$ & $\mathrm{CR}$ & Nil & $\begin{array}{l}\text { At } 16 \text { months } \\
\text { recurrence - Surgery followed by RT ( } 60 \text { Gy in } \\
30 \text { fractions). } \\
20 \text { months, no recurrence, alive }\end{array}$ \\
\hline Chaskis et al [13] & $69 / \mathrm{M}$ & Left parietal lobe & CR & Nil & 1 month, died (septic shock) \\
\hline Im et al [14] & $43 / \mathrm{M}$ & Left parietal lobe & CR & $\begin{array}{l}\text { RT ( } 59.4 \text { Gy in } \\
33 \text { fractions) }\end{array}$ & 3 years, no recurrence, alive \\
\hline $\begin{array}{l}\text { Sorimachi et al } \\
\text { [15] }\end{array}$ & $37 / F$ & Pineal gland & STR & Nil & $\begin{array}{l}\text { At } 13 \text { months, recurrence - Surgery (CR). } \\
7 \text { months, no recurrence, alive }\end{array}$ \\
\hline O'Brien et al [16] & $26 / F$ & $\begin{array}{l}\text { Left cerebellopontine } \\
\text { angle }\end{array}$ & STR & RT (Proton therapy) & 1 year, no tumour progression, alive \\
\hline Park et al [17] & $21 / \mathrm{F}$ & Right thalamus & $\mathrm{CR}$ & RT (60.8 Gy) & 6 months, no recurrence, alive \\
\hline Dulou et al [18] & $70 / F$ & Left frontal lobe & $\mathrm{CR}$ & $\begin{array}{l}\text { RT ( } 60 \text { Gy in } 30 \\
\text { fractions) + Chemotherapy } \\
\text { (ifosfamide) }\end{array}$ & 10 months, died \\
\hline Govind et al [19] & $40 / M$ & Left frontal lobe & CR & Nil & 6 months, no recurrence, alive \\
\hline
\end{tabular}


Table 1. Primary intracranial EMC cases reported in literature. (Continued)

\begin{tabular}{|c|c|c|c|c|c|}
\hline Rodgers et al [20] & $16 / M$ & Right thalamus & STR & $\begin{array}{l}\text { Re-resection followed by proton } \\
\text { therapy ( } 30.67 \text { CGE to primary } \\
\text { site and } 36.30 \text { CGE to cranio- } \\
\text { spinal axis) \& Pazopanib }\end{array}$ & 16 months, died \\
\hline Qin et al [21] & $41 / \mathrm{F}$ & Left cerebellum & STR & $\begin{array}{l}\text { RT ( } 56 \text { Gy in } 28 \text { fractions) + } \\
\text { Chemotherapy (Temozolomide) }\end{array}$ & 19 months, no recurrence, alive \\
\hline Rashed et al [22] & $65 / F$ & $\begin{array}{l}\text { Left parietooccipital } \\
\text { space }\end{array}$ & STR & RT (60 Gy in 30 fractions) & 6 months, died \\
\hline Akakin et al [23] & $35 / F$ & Falx cerebri & $\mathrm{CR}$ & NR & $\begin{array}{l}\text { Recurrence at } 2 \text { months - Surgery followed by } \\
\text { RT ( } 18 \text { Gy in } 1 \text { fraction). } \\
\text { At } 9 \text { months from previous treatment - } \\
\text { second recurrence: Surgery followed by RT } \\
\text { ( } 15 \text { Gy in } 1 \text { fraction) }\end{array}$ \\
\hline Present case & $27 / M$ & Right lateral ventricle & CR & $\begin{array}{l}\text { Adjuvant RT ( } 54 \text { Gy in } 30 \\
\text { fractions) }\end{array}$ & At 29 months, no recurrence, alive \\
\hline
\end{tabular}

F, Female; M, Male; CR, Complete resection; STR, Sub-total resection; RT, Radiotherapy; Gy, Gray; CGE, Cobalt gray equivalent

\section{Conclusions}

Primary intracranial EMC is an extremely rare malignancy of central nervous system. It is always advisable to do a thorough histopathological examination with IHC markers in all intracranial neoplasms to identify the true histology. EMC should be considered as one of the differential diagnosis, especially when tumour cells appear bland in myxoid matrix with associated cord like arrangement and suggestive IHC markers. Combined modality of treatment with surgery followed by adjuvant radiotherapy results in good local control.

\section{Ethical approval and consent to participate}

Not applicable.

\section{Consent for publication}

Consent for publication was obtained from the patient.

\section{Competing interests}

The authors declare that they have no competing interests.

\section{Funding}

The authors declare that no specific grant was obtained for this research from any funding agency in the public, commercial or not-for-profit sectors in the design of the study and collection, analysis and interpretation of data and in writing the manuscript. 


\section{Authors' contributions}

Dr Deleep Kumar Gudipudi contributed to concept, design and proof reading of manuscript. Dr Vinodh Kumar Selvaraj contributed to data collection, review of literature and manuscript writing. Dr Rachna Khera and Dr Sudha Murthy contributed to preparing the histopathology images and in manuscript writing of the pathologic description of the case.

\section{Acknowledgments}

The authors would like to acknowledge Dr Veeraiah Koppula, Head of Department of Radiology, for MRI images.

\section{References}

1. Hassounah M, Al-Mefty O, and Akhtar M, et al (1985) Primary cranial and intracranial chondrosarcoma. A survey Acta Neurochir (Wien) 78 123-132 https://doi.org/10.1007/BF01808691

2. Bahr AL and Gayler BW (1977) Cranial chondrosarcomas. Report of four cases and review of literature Radiology 124 151-156 https:// doi.org/10.1148/124.1.151 PMID: 866631

3. Gacek RR (1975) Diagnosis and management of primary tumors of the petrous apex Ann Otol Rhinol Laryngol 84 1-20 https://doi. org/10.1177/0003489475084S1801 PMID: 1115494

4. Bingaman KD, Alleyne $\mathrm{CH}$, and Olson JJ (2006) Intracranial extraskeletal mesenchymal chondrosarcoma: case report Neurosurgery 46 207-212 https://doi.org/10.1093/neurosurgery/46.1.207

5. Harsh GR 4th and Wilson CB (1984) Central nervous system mesenchymal chondrosarcoma: case report J Neurosurg 61 375-381 https://doi.org/10.3171/jns.1984.61.2.0375 PMID: 6539815

6. Oliveira AM, Sebo TJ, and McGrory JE, et al (2000) Extraskeletal myxoid chondrosarcoma: a clinicopathologic, immunohistochemical, and ploidy analysis of 23 cases Mod Pathol 13 900-908 https://doi.org/10.1038/modpathol.3880161 PMID: 10955458

7. Scott RM, Dickersin GR, and Wolpert SM, et al (1976) Myxochondrosarcoma of the fourth ventricle J Neurosurg 44 386-369 https://doi. org/10.3171/jns.1976.44.3.0386 PMID: 1249620

8. Smith TW and Davidson RI (1981) Primary meningeal myxochondrosarcoma presenting as a cerebellar mass: case report Neurosurgery 8 577-581 https://doi.org/10.1227/00006123-198105000-00012 PMID: 7266799

9. Salcman M, Scholtz H, and Kristt D, et al (1992) Extraskeletal myxoid chondrosarcoma of the falx Neurosurgery 31 344-348 https://doi. org/10.1227/00006123-199208000-00021 PMID: 1513440

10. Sato K, Kubota T, and Yoshida K, et al (1993) Intracranial extraskeletal myxoid chondrosarcoma with special reference to lamellar inclusions in the rough endoplasmic reticulum Acta Neuropathol 86 525-528 https://doi.org/10.1007/BF00228591 PMID: 8310804

11. Sala F, Talacchi A, and Beltramello A, et al (1998) Intracranial myxoid chondrosarcoma with early intradural growth J Neurosurg Sci 42 159-163

12. Gonzalez-Lois C, Cuevas C, and Abdullah O, et al (2002) Intracranial extraskeletal myxoid chondrosarcoma: case report and review of the literature Acta Neurochir 144 735-740 https://doi.org/10.1007/s00701-002-0949-y PMID: 12181708

13. Chaskis C, Michotte A, and Goossens A, et al (2002) Primary intracerebral myxoid chondrosarcoma. Case illustration J Neurosurg 97228 https://doi.org/10.3171/jns.2002.97.1.0228 PMID: 12134922 
14. Im SH, Kim DG, and Park IA, et al (2003) Primary intracranial myxoid chondrosarcoma: report of a case and review of the literature J Korean Med Sci 18 301-307 https://doi.org/10.3346/jkms.2003.18.2.301 PMID: 12692436 PMCID: 3055022

15. Sorimachi T, Sasaki O, and Nakazato S, et al (2008) Myxoid chondrosarcoma in the pineal region J Neurosurg 109 904-907 https://doi. org/10.3171/JNS/2008/109/11/0904 PMID: 18976082

16. O'Brien J, Thornton J, and Cawley D, et al (2008) Extraskeletal myxoid chondrosarcoma of the cerebellopontine angle presenting during pregnancy Br J Neurosurg 22 429-432 https://doi.org/10.1080/02688690701780127

17. Park JH, Kim MJ, and Kim CJ, et al (2012) Intracranial extraskeletal myxoid chondrosarcoma: case report and literature review $J$ Korean Neurosurg Soc 52 246-249 https://doi.org/10.3340/jkns.2012.52.3.246 PMID: 23115670 PMCID: 3483328

18. Dulou R, Chargari C, and Dagain A, et al (2012) Primary intracranial extraskeletal myxoid chondrosarcoma Neurol Neurochir Pol 46 76-81 https://doi.org/10.5114/ninp.2012.27176 PMID: 22426765

19. Govind M, Radheysham M, and Achal S, et al (2015) Primary intracranial extraosseous myxoid chondrosarcoma of dominant frontal lobe Rom Neurosurg 3 324-328

20. Rodgers S, Wadhwani N, and Tomita T (2016) Intracranial extraskeletal myxoid chondrosarcoma of the pineal region in a child and literature review J Neurosurg Imaging Tech 1(1) 1-6

21. Qin Y, Zhang H, and Ke C, et al (2017) Primary extraskeletal myxoid chondrosarcoma in cerebellum. A case report with literature review Medicine 9647 https://doi.org/10.1097/MD.0000000000008684

22. Rashed H, Abdelrahman A, and Elmesallamy W, et al (2017) Primary intracranial myxoid chondrosarcoma: a case report J Interdisciplinary Histopathol 5(4) 1 https://doi.org/10.5455/jihp.20170726091652

23. Akakin A, Urgun K, and Eksi MS, et al (2018) Falcine myxoid chondrosarcoma: a rare aggressive case Asian J Neurosurg 13 68-71 https:// doi.org/10.4103/1793-5482.181116 PMID: 29492125 PMCID: 5820899

24. Korten AG, Berg HJ, and Spincemaille GH, et al (1998) Intracranial chondrosarcoma: review of the literature and report of 15 cases J Neurol Neurosurg Psychiatry 65 88-92 https://doi.org/10.1136/jnnp.65.1.88 PMID: 9667567 PMCID: 2170168

25. Bosma JJD, Kirollos RW, and Broome J, et al (2001) Primary intradural classic chondrosarcoma: case report and literature review Neurosurgery 48 420-423 PMID: 11220388

26. Nagata S, Sawada K, and Kitamura K (1986) Chondrosarcoma arising from the falx cerebri Surg Neurol 25 505-509 https://doi. org/10.1016/0090-3019(86)90092-3 PMID: 3961667

27. Kothari N, Law M, and Cha S, et al (2003) Conventional and perfusion MRI imaging of parafalcine chondrosarcoma AJNR 24 245-248

28. Vergeer RA, Vink R, and Avenarius JK, et al (2012) A 71-year-old woman with an intracranial dural-based mesenchymal chondrosarcoma J Clin Neurosci 19 1170-1171 https://doi.org/10.1016/j.jocn.2011.08.042 PMID: 22658242

29. Scheithauer BW and Rubinstein LJ (1978) Meningeal mesenchymal chondrosarcoma: report of 8 cases with review of the literature Cancer 42 2744-2752 https://doi.org/10.1002/1097-0142(197812)42:6<2744::AID-CNCR2820420633>3.0.CO;2-L PMID: 365318

30. Enzinger FM and Shiraki M (1972) Extraskeletal myxoid chondrosarcoma. An analysis of 34 cases Hum Pathol $3421-435$ https://doi. org/10.1016/S0046-8177(72)80042-X PMID: 4261659

31. Drilon A.D, Popat S, and Bhuchar G, et al (2008) Extraskeletal myxoid chondrosarcoma: a retrospective review from 2 referral centers emphasizing long-term outcomes with surgery and chemotherapy Cancer 113 3364-3371 https://doi.org/10.1002/cncr.23978 PMID: 18951519 PMCID: 2779719 
32. Chandler JP, Yashar P, and Laskin WB, et al (2004) Intracranial chondrosarcoma: a case report and review of literature $J$ Neurooncol 68 33-39 https://doi.org/10.1023/B:NEON.0000024728.72998.7d PMID: 15174519

33. Lee YY, Van Tassel P, and Raymond AK (1988) Intracranial dural chondrosarcoma AJNR 9 1189-1193 PMID: 3143243

34. Folpe AL, Agoff SN, and Willis J, et al (1999) Parachordoma is immunohistochemically and cytogenetically distinct from axial chordoma and extraskeletal myxoid chondrosarcoma Am J Surg Pathol 23 1059-1067 https://doi.org/10.1097/00000478-199909000-00008 PMID: 10478665

35. Sjogren H, Meis JM, and Kindblom LG, et al (1999) Fusion of EWS -related gene TAF2N to TEC in extraskeletal myxoid chondrosarcoma Cancer Res 59(20) 5064-5067 PMID: 10537274

36. Panagopulos I, Mertens F, and Isaksson M, et al (2002) Molecular genetic characterisation of EWS/CHN and RBP56/CHN fusion genes in extraskeletal myxoid chondrosarcoma Genes Chromosomes Cancer 35(4) 340-352 https://doi.org/10.1002/gcc.10127

37. Agaram NP, Zhang L, and Sung Y, et al (2014) Extraskeletal myxoid chondrosarcoma with non-EWSR1-NR4A3 variant fusions correlate with rhabdoid phenotype and high grade morphology Hum Pathol 45(5) 1084-1091 